\title{
STRATEGI PEMASARAN YANG DILAKUKAN \\ “RESTAURANT BLACK CANYON COFFEE" \\ DI PLAZA TUNJUNGAN III SURABAYA DALAM MEMASARKAN PRODUKNYA
}

\author{
${ }^{1}$ Dheenaz Malvinas Ticha, ${ }^{2}$ Achmad Daengs GS, \\ ${ }^{3}$ Moch. Rizaldy Rachmansyah \\ ${ }^{1,2}$ Universitas 45 Surabaya \\ 1email :dticha@yahoo.com \\ 2email : bumigora80@gmail.com \\ ${ }^{3}$ Universitas Ciputra, Surabaya \\ ${ }^{3}$ email : mrizaldy01@magister.ciputra.ac.id
}

\begin{abstract}
ABSTRAK
Untuk memenangkan persaingan, faktor kepuasan konsumen merupakan hal yang sangat penting, karena itu pemasar selalu diharapkan untuk mengadakan pembaharuan serta pengenalan produk terhadap konsumen yang ingin dicapainya. Untuk tetap mempertahankan konsumen. Black Canyon Coffee restoran dan juga coffee shop dengan konsep franchise dari Thailand yang ada di Tunjungan Plaza 3 lantai 4 dan Surabaya Town Square, juga harus melakukan strategi pemasaran untuk memasarkan produknya. Kesimpulan pada penelitian ini, konsumen Black Canyon Coffee Restoran adalah: (1) laki-laki berusia 21-35 tahun; (2) konsumen memperoleh informasi dari teman 47\%, 37\% dari relasi bisnis, 135 dari keluarga; (3) keinginan konsumen untuk kembali datang ke Black Canyon Coffee Restoran, 44\% menyatakan mungkin, 37\% menyatakan ya. Strategi pemasaran yang dilakukan oleh Black Canyon Coffee Restoran adalah meningkatkan kecepatan penyajian dan kualitas makanan, meningkatkan kebersihan restoran, keramahan dan kerapihan penampilan staf. Peningkatan promosi baik melalui media cetak maupun media elektronik, ataupun dengan papan reklame supaya lebih dikenal masyarakat keberadaannya.
\end{abstract}

Kata kunci : kualitas layanan, kepuasan konsumen, strategi pemasaran, produk.

\begin{abstract}
To winning the competition, the factors of customer satisfaction are very important things, because of that, the marketers are always expected to hold a renewal and introduction of products to the consumer who wants to be reached to retain the customers. Black Canyon Coffee restaurants and also a coffee shop of franchise concept from Thailand that located at Tunjungan Plaza 3 floors 4 and at Surabaya Town Square also have to do a marketing strategy to marketing their products. The conclusion of this research, consumers of Black Canyon Coffee restaurants are: (1) men who aged of 21-35 years; (2) consumers that obtain information from the friend by $47 \%, 37 \%$ are from the business relationship, $13 \%$ are from the family; (3) consumers desires to come again to the Black Canyon Coffee restaurant as much as $44 \%$ are said maybe, and $37 \%$ are said yes. The marketing strategy that undertaken by Black Canyon Coffee restaurant is to increasing presentation speed and food quality, increasing cleanliness of restaurant, hospitality and neatness of staffs' appearance. The increasing of promotion both through of printing and electronic media, or by a billboard so that its presences are more to be known by the public.
\end{abstract}

Keywords : service quality, customer satisfaction, marketing strategy, product. 


\section{PENDAHULUAN}

Dewasa ini bisnis makanan berkembang sangat marak di kota Surabaya. hal ini dapat dilihat dari banyaknya restoran yang muncul, baik dalam skala kecil maupun skala besar, sehingga menyebabkan persaingan semakin ketat karena konsumen memiliki lebih banyak pilihan tempat untuk mangkonsumsi makanan dan minuman. Hal tersebut menyebabkan pelaku bisnis restoran dituntut untuk semakin selektif di dalam menentukan konsumen yang dibidik agar bidang usaha yang dikelola bisa berjalan dengan linear sesuai dengan tujuan yang ingin dicapai.

Untuk memenangkan persaingan, faktor kepuasan konsumen merupakan hal yang sangat penting. Oleh karena itu. pemasar selalu diharapkan untuk mengadakan pembaharuan serta melaksanankan promosi pengenalan produk terhadap konsumen yang ingin dicapainya. Pemasar tidak saja harus mampu menjual produk atau jasanya, melainkan juga harus mempelajari apa yang menjadi kebutuhan dan keinginan konsumen di masa sekarang dan di masa yang akan datang serta mengetahui bagannana menyajikan alternatif terbaik kepada konsumen yang jadi sasaran utamanya, sehingga pemasar dapat memasarkan dan menyesuaikan produknya menjadi lebih unggul dari para pesaingnya.Setelah mengetahui situasi dan kondisi persaingan yang semakin ketat antar perusahaan dimana perusahaan tetap menginginkan bagaimana mempertahankan konsumennya agar tidak menurun pimpinan perusahaan diharapkan juga cepat tanggap terhadap perubahan yang terjadi di sekitarnya.

Hal ini sungguh sangat penting karena apabila pimpinan perusahaan terlambat menyadari perubahan yang terjadi di sekitarnya maka hal itu dapat memberi celah bagi para pesaing untuk menaikan penjualannya.Dalam rangka menghadapi persaingan tersebut, untuk tetap mempertahankan konsumen serta untuk mendapatkan keuntungan dalam jangka waktu panjang dengan tidak lupa memberi kepuasan pada konsumen, maka pengelola restoran diharapkan lebih selektil di dalam melakukan analisa selera dan perilaku konsumen di pasar, sehingga tercipta permintaan yang efektif. Black Canyon Coffee adalah salah satu restoran yang juga coffee shop dengan konsep franchise dari Thailand. Di Surabaya sendiri sudah berdiri 2 outlet yaitu di Surabaya Town Square adalah outlet pertama dan Tunjungan Plaza 3 lt.4 adalah outlet kedua. Lokasi outlet kedua ini sangat strategis dengan segmen konsumen family dan anak muda di Tunjungan Plaza dimana kunjungan konsmen ke mall tinggi. Dengan konsumen dari berbagai kalangan dan fasilitas juga pelayanan yang sama dengan outlet lainnya diharapkan outlet kedua lebih berkembang dibanding outlet pertama. Namun hasil yang diperoleh tidak sesuai dengan harapan. (Daengs, Achmad, Mahjudin, 2014 : 115).

\section{TINJAUAN LITERATUR}

Pemasaran merupakan salah satu dari kegiatan-kegiatan pokok yang dilakukan oleh perusahaan dalam usaha mempertahankan kelangsungan usahanya untuk berkembang serta mendapatkan laba. Beberapa ahli mengemukakan berbagai definisi pemasaran Menurut Kotler (1997:9), definisi dari pemasaran adalah sebagai berikut:

"Marketing is a social and managerial process by which individuals and group obtain what they need mid want through creating and exchanging products of value with other."

Ada juga pendapat lain dari Stanton (1991:5-6), yang mendefinisikan tentang pemasaran sebagai berikut

"Marketing is a total system of business activities designed to plan, price, promote, and distribute wants satisfying goods and services to present and potential customers."

Pemasaran akan berhasil apabila pemasaran itu selalu diarahkan pada pemuasan kebutuhan dan keinginan pembeli yang merupakan suatu hal yang tidak dapat ditawar lagi pembeli akan memberikan balas jasa berupa loyalitas bagi penjual apabila pembeli merasa setelah salah satu keinginan atau kebutuhannya dapat dipenuhi.

Jadi secara garis besar dapat ditarik kesimpulan bahwa pemasaran bukan hanya merupakan kegiatan menjual saja, melainkan suatu proses atau rangkaian kegiatan yang terus-menerus dan terpadu, yaitu mulai dari kegiatan untuk mengidentifikasikan produk atau jasa apa yang dibutuhkan dan diinginkan konsumen, penentuan harga yang sesuai, penentuan cara promosi yang efektif, sampai dengan kegiatan menyalurkan barang atau jasa kepada konsumen. 
Strategi pemasaran adalah logika pemasaran, dan berdasarkan itu, unit bisnis diharapkan untuk mencapai sasaran-sasaran pemasarannya. Strategi pemasaran perusahaan terdiri dari pengambilan keputusan tentang biaya pemasaran dari perusahaan, bauran pemasaran, dan alokasi pemasaran dalam hubungannya dengan keadaan lingkungan yang diharapkan dalam kondisi persaingan, adanya asimetri informasi. (Daengs, Achmad, Mahjudin, 2014:44)

Strategi pemasaran menyeluruh perusahaan tercermin dalam rencana strategi pemasaran perusahaan (Corporate Marketing Plan) yang disusun. Rencana strategi pemasaran perusahaan adalah suatu rencana pemasaran jangka panjang yang bersifat menyeluruh dan strategis, yang merumuskan berbagai strategi dan program pokok dibidang pemasaran perusahaan pada suatu jangka waktu tertentu dalam jangka panjang dimasa depan. Ciri penting rencana strategis pemasaran perusahaan ini adalah sebagai berikut:

a. Titik-tolak penyusunannya melihat perusahaan secara keseluruhan

b. Diusahakan dampak kegiatan yang direncanakan bersifat menyeluruh

c. Dalam penyusunannya diusahakan untuk memahami kekuatan yang mempengaruhi perkembangan perusahaan

d. Jadwal waktu/timing yang ditentukan adalah yang sesuai dan mempertimbangkan fleksibilitas dalam menghadapi perubahan, dan

e. Penyusunan rencana dilakukan secara realistis dan relevan dengan lingkungan yang dihadapi.

Pada saat sekarang ini maupun saat kedepan, strategi pemasaran yang diterapkan oleh suatu perusahaan harus disesuaikan tidak hanya pada sasaran konsumen semata, tetapi juga pada para pesaing yang mengincar pasar sasaran konsumen yang sama. Perusahaan sebelum menetapkan dan menjalankan strateginya hendaklah terlebih dahulu malakukan analisa SWOT (Strength, Weakness, Opportunity and Treath) yaitu melihat dan menganalisa kekuatan, kelemahan, peluang, dan ancaman yang dimilikinya sendiri dan juga yang dimiliki oleh para pesaingnya.

Tabel 1

Strategi Untuk Setiap Posisi Bisnis

\begin{tabular}{|l|l|l|}
\hline \multicolumn{1}{|c|}{ POSISI } & \multicolumn{1}{|c|}{ REAKTIF } & \multicolumn{1}{c|}{ PROAKTIF } \\
\hline LEADER & Balas & - Pengembangan pasar \\
& Persaingan harga & - Penelitian dan pengembangan \\
\hline CHALLENGER & Follow the leader & - Menantang \\
& - Me too & - Menyerang \\
\hline FOLLOWER & Status Quo & - Cari pasar baru \\
& Me too & - Cari segmen pasar baru \\
& & - Market niche \\
\hline
\end{tabular}

Strategi bersaing bergantung pada besar dan posisi masing-masing perusahaan dalam pasar. Perusahaan besar mampu menerapkan strategi tertentu, yang jelas tidak bisa dilakukan oleh perusahaan kecil. Tetapi hanya dengan sekala besar saja tidaklah cukup, karena ada beberapa strategi bagi perusahaan besar yang mampu menjamin keberhasilannya, akan tatapi ada juga strategi yang dapat merugikan dirinya sendiri. Dan bukanlah merupakan sesuatu hal yang jarang terjadi bahwa perusahaan kecil dengan strateginya sendiri mampu rnenghasilkan tingkat keuntungan yang sama atau bahkan lebih baik daripada yang diperoleh perusahaan besar. Sehubungan dengan besarnya usaha, maka dapat dibedakan menjadi empat kelompok usaha, yaitu:

1. Market Leader menguasai $40 \%$ pasar

2. Market Challanger menguasai $30 \%$ pasar

3. Market Follower menguasai $20 \%$ pasar

4. Market Nicher menguasai $10 \%$ pasar

\section{Market Leader}

Perusahaan seperti ini rnemegang bagian terbesar dalam pasar, biasanya perusahaan-perusahaan lain mengikuti tindakan-tindakan perusahaan dalam hal perubahan harga, pengenalan produk baru, pencakupan saluran distribusi, dan intensitas promosi. Perusahaan ini menjadi titik pusat orientasi para pesaing. Ia merupakan perusahaan yang ditantang, ditiru, atau 
dijauhi. Kehidupan pemimpin pasar sungguh tidaklah mudah, terkecuali bila perusahaan itu memang memiliki promosi resmi. Perusahaan tersebut senantiasa mempertinggi kewaspadaannya sebab para pesaingnya selalu mencari dan mencoba memanfaatkan kelemahannya, meski sekecil apapun. Perusahaan yang dominan selalu ingin tetap menjadi nomor satu, oleh sebab itu, perusahaan-perusahaan seperti ini bjasanya mengembangkan strategi.

\section{Market Challanger}

Perusahaan yang mempunyai urutan kedua atau lebih rendah lagi didalam pasar bisa disebut "runner up" atau "Penyusul". Mereka dapat menyerang Market leader dan pesaing-pesaing lainnya dalam suatu usaha yang gencar merebut bagian pasar, perusahaan inilah yang disebut Market Challanger.

\section{Market Follower}

Perusahaan seperti ini lebih suka menawarkan hal-hal yang serupa, biasanya dengan meniru produk perusahaan yang memimpin. Setiap market follower selalu menonjolkan sifat khasnya kepada target pasar, misalnya lokasi, jasa pelayanan, atau keuangannya. Strategi umum yang biasa dilakukan oleh maeket follower yaitu:

- Mengikuti dari dekat. Market follower berusaha menyamai perusahaan pemimpin pasar pada sebanyak mungkin segmen pasar dan wilayah bauran pemasaran.

- Mengikuti dari jauh. Dalam strategi ini market follower membuat beberapa differensiasi, namun tetap mengikuti market leader dalam hal pembauran pasar.

- Mengikuti secara selektif. Market follower mengikuti dengan dekat beberapa hal yang dilakukan market leader, namum pada hal-hal yang lain perusahaan berjalan dengan sendiri.

\section{Market Nicher}

Perusahaan seperti ini, menyandang berbagai nama seperti; penggarap relung pasar, spesialisasi pasar, perusahaan ambang pintu, atau perusahaan tumpuan. Market nicher menempati sebagian kecil dari seluruh pasar yang ada. Perusahaan jenis ini mencoba masuk kesatu atau lebih celah-celah pasar yang aman dan menguntungkan yang dilupakan atau terlewatkan oleh perusahaan besar. Umumnya market micher adalah perusahaan yang mempunyai spesialisasi tertentu dan keahlian yang khas didalam pasar, konsumen, produk atau lini-lini dalam bauran pemasaran.

Menurut Mangkunegara (1988:31) perilaku konsumen adalah tindakan yang dilakukan oleh individu, kelompok, atau organisasi yang berhubungan dengan proses pengambilan keputusan dalarn mendapatkan, menggunakan barang-barang atau jasa ekonomis yang dapat dipengaruhi oleh lingkungan.

Berdasarkan definisi di atas, maka dapat disimpulkan bahwa perilaku konsumen merupakan suatu studi untuk mengetahui bagaimana seseorang membuat keputusan pembelian, apa yang dibeli, kapan, dan dimana konsumen membeli barang atau jasa tersebut. Di dalam mempelajari perilaku konsumen ternyata tidak hanya mempelajari bagaimana seorang konsumen rnenentukan keputusan dalam melakukan pembelian, dimana melakukannya, dan kebiasaan-kebiasaan dalam membeli, tetapi juga mempelajari faktor- - faktor yang mempengaruhi perilaku konsumen tersebut, dengan layanan berkualitas. (Daengs, Achmad, Mahjudin, 2012:423).

Menurut Assael (1992:14), kita bisa melihat bahwa ada 3 aspek yang mempengaruhi perilaku konsumen di dalam pengambilan keputusan, yaitu individual consumers, environmental influences, dan marketing strategies. Ketiga aspek tersebut, digolongkan ke dalam faktor internal dan faktor eksternal. Seperti terlihat pada gambar 1 maka dapat dijelaskan bahwa aspek individual consumers masuk ke dalam faktor internal. Sedangkan aspek environmental influences dan marketing strategies masuk ke dalam faktor eksternal. Ketiga aspek dari dua faktor tersebut akan menghasilkan satu keputusan bagi konsumen untuk memberi tanggapan produk yang ditawarkan, dimana merupakan titik puncak bagi konsumen tertarik atau tidaknya konsumen terhadap suatu produk yang ditawarkan. 
Assael (1992:38) menjelaskan lebih dalam mengenai 2 faktor tersebut sebagai berikut :

Untuk menjawab pertanyaan tersebut tidaklah mudah. Salah satu cara untuk memahami hal tersebut adalah dengan mengetahui faktor-faktor yang mempengaruhi pembelian. Faktor-faktor yang mempengaruhi perilaku konsumen adalah Setiadi (2003:40)

\section{Faktor Budaya}

Faktor-faktor budaya memberikan pengaruh paling luas dan dalam terhadap tingkah laku konsumen. Pemasar harus mengetahui peran yang dimainkan oleh budaya, subbudaya dan kelas sosial.

\section{Faktor Sosial}

Tingkah laku konsumen juga dipengaruhi oleh faktor-faktor sosial, keluarga serta peran dan status sosial.

\section{Faktor Psikologis}

Pilihan barang yang dibeli seseorang lebih lanjut dipengaruhi oleh empat faktor psikologis yang penting yaitu motivasi, persepsi, pengetahuan, serta keyakinan dan sikap.

\section{Faktor eksternal}

Faktor-faktor eksternal adalah faktor-faktor yang berasal dari luar diri individu. Faktor tersebut adalah dari lingkungan dan strategi pemasaran perusahaan.

\section{Proses Pengambilan Keputusan}

Suatu keputusan melibatkan pilihan alternatif. Pemasar biasanya tertarik pada perilaku konsumen, terutama pilihan mereka. Semua aspek pengaruh dan kognisi dilibatkan dalam pengambilan keputusan konsumen. Akan tetapi inti dari pengambilan keputusan konsumen adalah proses pengintegrasian yang mengkombinasikan pengetahuan untuk mengevaluasi alternatif-alternatif dan memilih salah satu diantaranya

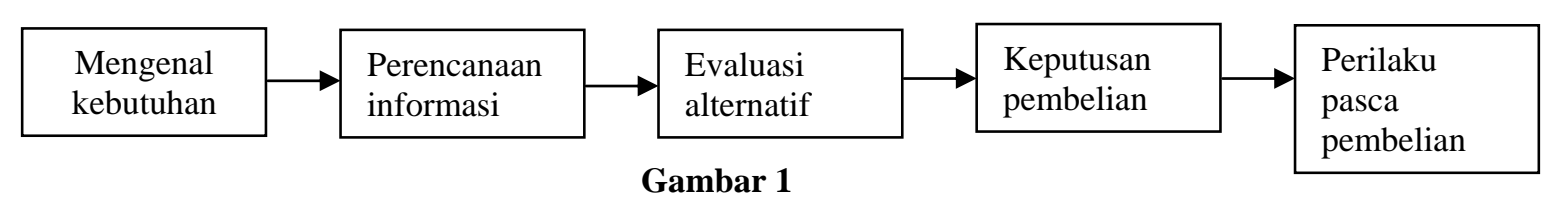

Gambar 1

Sumber : Setiadi (2008: 16)

Proses Pengambilan Keputusan Pembelian

\section{Target Pasar}

Di dalam memilih segmen pasar yang akan dibidik, perusahaan diharapkan untuk memilih satu atau lebih segmen yang berharga untuk dirnasuki. Perusahaan harus memutuskan berapa banyak dan bagaimana segmen yang akan dilayaninya. Menurut Kotler (1993:391) suatu pasar sasaran terdiri dari sekumpulan pembeli yang mempunyai kebutuhan atau karakteristik yang sama, yang ingin dilayani oleh perusahaan.

a) Konsentrasi pada segmen tunggal

Perusahaan memiliki satu segmen tunggal dan hanya beroperasi di dalam segmen tersebut. Boleh jadi perusahaan tersebut mempunyai dana yang sangat terbatas dan segmen tersebut mungkin merupakan segmen dimana tidak ada satu pesaing pun yang masuk membidik segmen tersebut.

b) Spesialisasi Terpilih

perusahaan memilih beberapa segmen yang masing-masing menarik dan disesuaikan dengan tujuan serta sumber daya perusahaan. Mungkin hanya sedikit, atau tidak ada hubungan antar segmen, tapi setiap segmen berpotensi sebagai penghasil uang. Strategi jangkauan multi segmen ini mempunyai keuntungan dibandingkan jangkauan segmen tunggal dalam hal penyebaran resiko perusahaan. Bahkan jika satu segmen menjadi tidak menarik, 
perusahaan tersebut masih bisa memperoleh aliran kas dari segmen-segmen lain.

c) Spesialisasi Produk

Disini perusahaan berkonsentrasi pada pembuatan suatu produk tertentu yang

dijualnya ke beberapa segmen. Contohnya pembuatan mikroskop yang tidak hanya

dijual di laboratorium saja, namun juga di universitas, rumah sakit, dan lain sebagainya

\section{Bauran Pemasaran}

Strategi pemasaran dapat juga dipahami suatu rencana untuk memperbesar pengaruh terhadap pasar, baik dalam jangka pendek maupu jangka panjang yang didasarkan pada riset pasar, penilaian, perencanaan produk, promosi dan perencanaan penjualan distribusi. Salah satu strategi pemasaran yang dapat diambil oleh perusahaan aalah bauran pemasaran (marketing mix) .

Palmer (1998:7) mendefinisikan bauran pemasaran sebagai serangkaian variabel-variabel pemasaran yang terkendali yang dibaurkan oleh perusahaan untuk menghasilkan tanggapan konsumen yang diinginkannya dalam pasar.

Strategi pemasaran menjadi begitu penting dalam usaha karena jika dapat menciptakan strategi pemasaran yang baik maka akan menciptakan keunggulan yang bersinambungan, sulit ditiru pesaing dan kesuksesan, perusahaan dapat bertahan lebih lama karena 6 faktor yaitu Hasan (2009 : 51) :

1. Kemampuan menciptakan kompetensi khusus.

2. Kemampuan menciptakana persaingan tidak sempurna

3. Kemampuan melakukannpenyesuaian dengan lingkungan eksternal

4. Kemampuan menciptakan laba di atas rata-rata laba industri

5. Kemampuan menciptakan keseimbangan pesaing dan pelanggan

6. Memiliki kreativitas dan fleksibilitas

Menurut Tjiptono (2008 ; 30) bauran pemasaran adalah seperangkat alat yang dapat digunakan pemasar untuk membentuk karakteristik layanan yang ditawarkan kepada pelanggan. Alat-alat tersebut dapat digunakan untuk menyusun strategi jangka panjang dan merancang taktik jangka pendek.

Menurut Madura (2001 ; 83) bauran pemasaran adalah kombinasi dan strategi produk, penentuan harga, distribusi dan promosi yang digunakan untuk menjual produk. Menurut Palmer (1998:7-9), bauran pemasaran dikelompokkan menjadi 6 kelompok, yaitu :

\section{METODE PENELITIAN}

Data Primer dan Data Sekunder

\section{Teknik Analisis Data \\ Analisa Deskriptif}

Disini peneliti akan menguraikan hasil wawancara di lapangan secara deskriptif dengan memberikan pendapat mengenai alternatif-alternatif strategi pemasaran yang bisa diterapkan oleh pihak Restoran Black Canyon Coffee Tunjungan Plaza agar lebih dikenal oleh masyarakat luas.

\section{HASIL DAN PEMBAHASAN}

Kehadiran Black canyon Coffee di Surabaya sebagai coffee shop dan restoran dengan ciri khas Thailand greeting dan pelayanan yang friendly mendapat animo positif dari masyarakat Surabaya Pertama kali Black Canyon Coffee dibuka pada tahun 2008 di Surabaya Town Square yang menjadi ikon baru tempat hangout yang mendapat respon yang sangat positif. Dengan variasai lebih dari 100 macam menu makanan dan minuman, konsumen Surabaya semakin banyak pilihan untuk menikmati menu coffee shop ini dan sambutan khas Thailand "Sawas dee kha" . Melihat prospektus bisnis yang positif ini maka PT. Larazeta Yusmar Boga ikut menganbil franchise coffe shop ini untuk menyasar pasar Surabaya Pusat dengan landmark nya mall Tunjungan Plaza.

Dengan konsep interior yang berbeda lebih minimalis namun elegance, Black Canyon Coffee Tunjungan Plaza dengan 30 orang karyawan memberikan alternatif baru coffee shop di mall ini. Kapasitas duduk untuk area merokok cukup nyaman untuk dibuat small meeting dengan sofa yang nyaman dan mempunyai kapasitas \pm 30 orang. Area bebas rokok dengan kapsitas 50 orang memberikan kenyamanan pula. 
Data yang diperoleh menunjukkan bahwa sebagian besar responden yang berjumlah 47 orang dengan prosentase 47\% mengetahui Black Canyon Coffee Tunjungan Plaza dari relasi bisnis dengan cara dari mulut ke mulut. Begitu pula dengan 37 responden yang memiliki persentase sebanyak 37\% yang mengetalmi Black Canyon Coffee Tunjungan Plaza dari teman. Sedangkan untuk responden yang mengetahui Restoran Black Canyon Coffee Tunjungan Plaza dari keluarga memiliki prosentase sebesar 13\%, prosentase yang sangat kecil yaitu 0,03\% diketahui dari lain-lain publikasi. Hal ini dipengaruhi karena Black Canyon Coffee Tunjungan Plaza hampir tidak pernah menggunakan media iklan sebagai sarana promosinya, kecuali tent card yang diletakkan di masing-masing meja konsumen, menurut (Daengs, Achmad, Mursinto, Djoko, Ratnawati, Tri 2014:45) : This will drive the economic sectors in the economy in the future.

\section{KESIMPULAN}

1. Untuk klasifikasi responden diperoleh hasil bahwa sebagian besar responden adalah laki-laki dengan usia antara 21 - 35 tahun dan berstatus pengusaha / wiraswasta.

2. Responden paling banyak memperoleh informasi mengenai Black Canyon Coffee Tunjungan Plaza Surabaya dari teman dengan persentase sebanyak 47\% 37\% dari relasi bisnis , 13\% dengan keluarga. Sedangkan dari media iklan memiliki persentase yang sangat kecil, yaitu 0,03 \%. Hal ini mentuijukkan bahwa memang Black Canyon Coffee Tunjungan Plaza Surabaya hampir tidak pernah menggunakan media iklan sebagai sarana promosinya.

3. Persepsi responden terhadap Black Canyon Coffee Tunjungan Plaza Surabaya menyatakan cukup baik dengan rata-rata sebesar 26,75. Ada beberapa variabel yang memiliki nilai kurang baik, dimana hal ini perlu ditingkatkan, antara lain penyajian, keramahan, kecepatan dan kualitas makanan.

4. Meningkatkan pelayanan dalam hal kecepatan penyajian dan kualitas makanan. dalam industri F\&B kecepatan penyajian dan kualitas adalah vital dan nantinya berimbas pada kepuasan dan kepercayaan konsumen.

5. Mempertahankan dan meningkatkan kebersihan restoran dan keramahan staf, kerapihan penampilan.

6. Perlu dijadwalkan pelatihan setiap 3 bulan sekali guna mengkaji ulang kelebihan dan kekurangan yang dimiliki oleh restoran dan membuat pengurnuman siapa staf terbaik setiap bulannya guna memacu semangat staf untuk bekerja lebih baik.

\section{DAFTAR PUSTAKA}

Assael, Henry, (1992), Consumer Behavior and marketing Action, Kent Publishing, Boston.

Charles W. Lamb, Joseph F. Hair, Carl Mcdaniel. (2001). Pemasaran. Edisi Pertama, Salemba Empat, Jakarta. dan Pengendalian FE. Universitas Indonesia. Jakarta.

Daengs, Achmad, GS, Mahjudin, 2012. Increasing The Service Quality For Customer Satisfaction. JEBAV STIE Perbanas Surabaya, Vol. 15 No. 3, hal : 423-442.

Daengs, Achmad, GS, Mahjudin, Ririn, 2014. Pengaruh Earnings Management dan Level of Disclosure Terhadap Cost of Equity Capital Pada Perusahaan Publik Sektor Industri Real Estate dan Property Di Bursa Efek Indonesia. Majalah Ilmiah Bina Ekonomi FE UNPAR Bandung, Vol. 18, No. 1, hal : 43-68.

Daengs, Achmad, GS, Mursinto, Djoko, Ratnawati, Tri, 2014. The Influential of Private Investment, Public Investment on Economic Growth and Labor Absorption and Public Welfare of District/City in East Java Province. GSTF Journal on Business Review Vol. 3 No. 4, hal : 45-62.

Daengs, Achmad, GS, Mahjudin, 2014. Cost Of Quality Control To Improve Production Cost Efficiency And Sales Productivity. The Indonesian Accounting Review Journal, STIE Perbanas Surabaya, page : 115-128.

David, Fred R, (2006). Manajemen Strategi, Buku 1, Edisi kesepuluh, Salemba Empat: Jakarta.

Glueck, dan Jauch, L. R, (1999), Strategy Management and Business Policy, McGrawHill: New York.

Hasan, Ali, (2009). Marketing. Media Presindo : Jakarta. 
J. Setiadi, Nugroho, SE., MM., (2003), "Perilaku Konsumen Konsep dan Implikasi untuk Strategi dan Penelitian Pemasaran”. Jakarta: Kencana.

Kotler Phillips, (1993), Principli of Marketing, Prentice Hall Jnc : New Yersey.

Kotler, Philip \& Gary Amstrong. (2001). Prinsip-prinsip Pemasaran. Edisi Kedelapan, Jilid 2, Erlangga : Jakarta.

Kotler, Philip dan Susanto. (1999). Manajemen Pemasaran di Indonesia. Salemba Empat, Jakarta.

Kotler, Philip, (1997). Manajemen Pemasaran, Prenhallindo, Jakarta.

Kotler, Philip, (1994), Marketing strategy ; Analysis, Planning, Implementation and Control (8th ed). International Edition, Englewood Cliffs, Prentice Hall, New Jersey.

Kotler, Philip. (2005). Manajamen Pemasaran, Jilid 1 dan 2. PT. Indeks Kelompok Gramedia: Jakarta.

Kotler, Philip. (1993). Manajemen Pemasaran Analisis, Perencanaan, Implementasi

Madura, Jeff. (2001). Pengantar Bisnis. Penerbit Salemba Empat: Jakarta.

Malvinas, Dheenaz, (2011), Strategi pemasaran yang dilakukan "Restaurant Black Canyon Coffee” Di Plaza Tunjungan III Surabaya Dalam memasarkan produknya, Penelitian Mandiri, Surabaya, Universitas 45.

Palmer, Adrian, (1998), Principles of service Marketing, Edisi 13, United States of America: McGraw Hill

Pearce dan Robinson, (1997), Manajemen Strategis, Binarupa Aksara: Jakarta.

Prabu Mangkunegara, Anwar, (1988), Perilaku Konsumen (Edisi Revisi), Refika Aditama, Bandung.

Rangkuti, Freddy, (2005). Measuring Customer Satisfaction. PT. Gramedia Pustaka Utama: Jakarta.

Soekresno. (2000), Manajemen Food and Beverage. Edisi ke II. PT. Gramedia Pustaka Utama: Jakarta.

Stanton, William J., (1991), Prinsip Pemasaran, Erlangga, Jakarta.

Suratno, B., \& Rismiati, C. (2001). Pemasaran Barang dan Jasa. Kanisius : Yogyakarta.

Suryana Sumantri, (2001), Perilaku Organisasi, Universitas Padjadjaran : Bandung.

Tjiptono, Fandy, (2008), Strategi Pemasaran, Abdi Offset: Yogyakarta. 